\title{
Preferred protonation site of a series of sulfa drugs in the gas phase revealed by IR spectroscopy
}

\author{
Thomas Uhlemann ${ }^{1}$ (D), Giel Berden ${ }^{2}$ (D), and Jos Oomens ${ }^{2, \text { a }}$ (D) \\ 1 Physical Chemistry II, Ruhr-Univerität Bochum, 44780 Bochum, Germany \\ 2 FELIX Laboratory, Institute for Molecules and Materials, Radboud University, Toernooiveld 7, 6525 ED Nijmegen, \\ The Netherlands
}

Received 5 October 2020 / Accepted 30 November 2020 / Published online 21 January 2021

(C) The Author(s) 2021

\begin{abstract}
Sulfa drugs are an important class of pharmaceuticals in the treatment of bacterial infections. The amido/imido tautomerism of these molecules in their neutral form has been widely discussed in the literature. Here, we study the protonation preferences of sulfa drugs upon electrospray ionization (ESI) using IR action spectroscopy of the ionized gas-phase molecules in a mass spectrometer. Our set of molecules includes sulfanilamide (SA), the progenitor of the family of sulfa drugs, and the actual, sulfonamide nitrogen substituted, sulfa drugs sulfamethoxazole (SMX), sulfisoxazole (SIX), sulfamethizole (SMZ), sulfathiazole (STZ), sulfapyridine (SP) and sulfaguanidine (SG). IR multiple photon dissociation (IRMPD) spectra were recorded for the protonated sulfa drugs using a Fourier transform ion cyclotron resonance mass spectrometer (FT-ICR-MS) and an optical parametric oscillator/amplifier (OPO/OPA) as well as the FELIX free electron laser (FEL) as IR sources. The OPO provides tunable IR radiation in the NH stretch region $\left(3100-3700 \mathrm{~cm}^{-1}\right)$, while the FEL covers the fingerprint region $\left(520-1750 \mathrm{~cm}^{-1}\right)$. Comparison of experimental IR spectra with spectra predicted using density functional theory allowed us to determine the gas-phase protonation site. For $\mathrm{SA}$, the sulfonamide $\mathrm{NH}_{2}$ group was identified as the protonation site, which contrasts the situation in solution, where the anilinic $\mathrm{NH}_{2}$ group is protonated. For the derivative sulfa drugs, the favored protonation site is the nitrogen atom included in the heterocycle, except for SG, where protonation occurs at the sulfonamide nitrogen atom. The theoretical investigations show that the identified protonation isomers correspond to the lowest-energy gas-phase structures.
\end{abstract}

\section{Introduction}

Introduced in the 1930's sulfonamide antibiotics (sulfa drugs) were the first effective bacteriostats available as treatment against a variety of bacterial infections and are still widely used in veterinary medicine. Sulfanilamide (SA) was the first and structurally simplest representative of this family of drugs and remains the essential pharmacophore of sulfa drugs (Fig. 1) [1-3].

Sulfa drugs act by competitive inhibition of the enzyme dihydropteroate synthase (DHPS), so that $p$ aminobenzoic acid (PABA), the natural substrate, cannot bind and the bacteria are unable to synthesize 7,8-dihydropteroate, an intermediate in the synthesis of folate compounds [4-8]. The strongly pH-dependent solubility of sulfanilamide caused unwanted adverse health effects, which together with other adverse health effects, led to the synthesis of a plethora of derivatives $[3,7-12]$. The use of sulfonamide antibiotics in human medicine has decreased substantially since the arrival of antibiotics derived from microorganisms. Nevertheless, pharmaceuticals derived from sulfanilamide are still in use for many indications. Especially, the sulfonamide

\footnotetext{
a e-mail: jos.oomens@ru.nl (corresponding author)
}

group is currently also encountered in a variety of other classes of drugs targeting diseases other than bacterial infections [13].

Tandem mass spectrometry (MS/MS) is commonly used to identify sulfa drugs in various samples, so that theoretical and experimental studies on their detection and degradation, as well as their fragmentation pathways have been reported [14-16]. Geometryindependent neutral desorption extractive electrospray ionization (GIND-EESI) tandem mass spectrometry (MS/MS), for example, was successfully used to demonstrate that additives like sulfapyridine and several other sulfa drugs can be detected with high sensitivity in complex mixtures, in this case cosmetics [17]. Detection of sulfa drugs in food products as a consequence of their widespread use as antibiotics in livestock is of importance [18]. Furthermore, the subsequent environmental fate of sulfa drugs and detection in surface and groundwater was studied using MS/MS techniques [19].

The protonation/deprotonation states of sulfa drugs, and their prevalence in different media, have been the subject of numerous studies. Originally, protonation and deprotonation sites in sulfanilamide were derived from UV spectra under acidic and basic conditions, as well as from an analysis of the possible resonance 
structures and their influence on frequency and integrated absorbance of the UV bands [20-22]. Later also $\mathrm{pH}$-dependent Raman spectra were reported [23]. The $\mathrm{p} K_{\mathrm{a}}$ values reported for the two acid-base reactions of $\mathrm{SA}$ are, for example, $\mathrm{p} K_{\mathrm{a} 1}=1.78$ (expressed for the conjugate acid) and $\mathrm{p} K_{\mathrm{a} 2}=11.19-10.4[24,25]$. Therefore, sulfanilamide exists in its neutral form around $\mathrm{pH}$ 7. The corresponding equilibrium in solution ${ }^{+} \mathrm{H}_{3} \mathrm{~N}-$ $\mathrm{Ph}-\mathrm{SO}_{2}-\mathrm{NH}_{2}+\mathrm{OH}^{-} \rightleftharpoons \mathrm{H}_{2} \mathrm{~N}-\mathrm{Ph}-\mathrm{SO}_{2}-\mathrm{NH}_{2}+\mathrm{H}_{2} \mathrm{O}$ $\rightleftharpoons \mathrm{H}_{2} \mathrm{~N}-\mathrm{Ph}-\mathrm{SO}_{2}-\mathrm{NH}^{-}+\mathrm{H}_{3} \mathrm{O}^{+}$has been established $[26,27]$. Sulfisoxazole (SIX), in which one sulfonamide $\mathrm{H}$ atom is replaced by a doubly methylated isoxazole heterocycle, on the contrary, is a weak acid with a $\mathrm{p} K_{\mathrm{a}}$ value of 5.00, which is close to the $\mathrm{p} K_{\mathrm{a}}$ value of acetic acid (4.75). Protonation occurs at a $\mathrm{pH}$ value similar to sulfanilamide with the conjugate acid having a $\mathrm{p} K_{\mathrm{a}}$ value of 1.32 [25]. For sulfisoxazole as well as the structurally closely related sulfamethoxazole (SMX), the aromatic primary amino group is fully protonated in aqueous sulfuric acid [28]. Spectrophotometric titration was also used to determine the $\mathrm{p} K_{\mathrm{a}}$ values of sulfa drugs [14,21], which give protonation equilibria where the anilinic $\mathrm{NH}_{2}$ group is protonated. However, Ref. [29] concluded that the heterocyclic nitrogen atom is protonated in SMX, SIX, and STZ in solution. At lower $\mathrm{pH}$ values the anilinic $\mathrm{NH}_{2}$ group becomes protonated as well leading to a dication, as concluded from an observed blue-shift in their UV spectra, when compared with that of SA. In addition, comparison with the acid/base equilibrium of 5-aminoindazole had been reported earlier [30].

In general, sulfonamides have $\mathrm{p} K_{\mathrm{a}}$ values of 9-10 and for sulfonimides the average $\mathrm{p} K_{\mathrm{a}}$ values decrease to 5-6 due to resonance stabilization of the conjugate anion. $N$-Arylsulfonamides have $\mathrm{p} K_{\mathrm{a}}$ values of around 6-7 [27].

Protonation and deprotonation were studied in the solid-state as well. The crystal structures of co-crystals of sulfa drugs with acidic and basic compounds were resolved. For example, the crystal structure of cocrystals of SA and 3,5-dinitrosalicylic acid was determined, indicating that protonation occurs at the anilinic $\mathrm{NH}_{2}$ group [31]. SMX is protonated at the anilinic $\mathrm{NH}_{2}$ group as well when crystallized as a selenate, sulfate or oxalate salt [32]. Sulfapyridine is deprotonated at the sulfonamide $\mathrm{NH}$ group upon crystallization with piperidine [33]. Depending on the nature of the Rgroup bound to the sulfonamide, neutral sulfa drugs can exhibit amido-imido tautomerism (see Fig. 2). For some sulfa drugs, such as SP, the most stable tautomer is different for gas phase and solid state $[34,35]$.

A common technique to study isolated molecular ions in the gas phase is electrospray ionization mass spectrometry (ESI-MS). It has been shown that the ESI solvent and experimental conditions can influence the tautomeric form of the ion in the gas phase, which can also be different from the most stable form in the solution phase [36-45]. For PABA, a structural and electronic analog of sulfanilamide, the influence

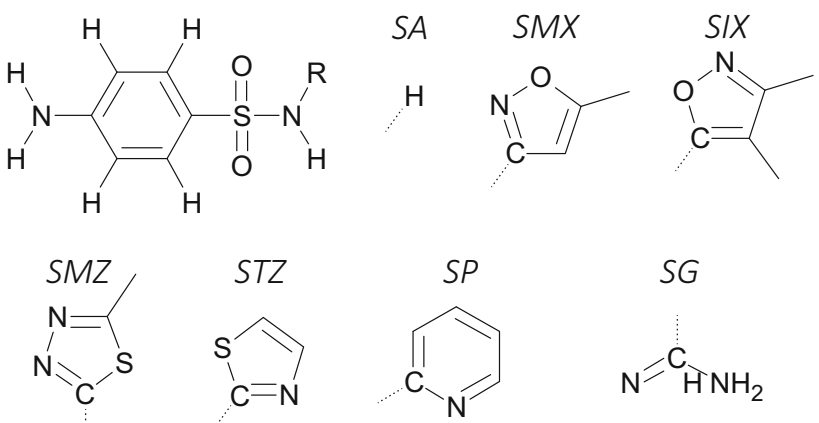

Fig. 1 Base chemical structure of the sulfanilamide derivatives (top left) and substituent groups $\mathrm{R}$ for the sulfa drugs investigated, where the dashed line indicates the link to the sulfanilamide moiety: sulfanilamide (SA), sulfamethoxazole (SMX), sulfisoxazole (SIX), sulfamethizole (SMZ), sulfathiazole (STZ), sulfapyridine (SP), and sulfaguanidine (SG). The amido tautomer is depicted in all cases; in the imido tautomer, the sulfonamide proton is on the nitrogen atom of the $\mathrm{R}$ group

of the ESI solvent on the protonation site of the ion obtained in the gas phase was reported $[39,45]$. The $\mathrm{O}$-protonated ion, which is the most stable tautomer in the gas phase on account of efficient charge delocalization, was the species produced by ESI when using a $\mathrm{CH}_{3} \mathrm{OH} / \mathrm{H}_{2} \mathrm{O}$ mixture as solvent. In contrast, a mixture of $\mathrm{CH}_{3} \mathrm{CN} / \mathrm{H}_{2} \mathrm{O}$ as solvent led to the $\mathrm{N}$-protonated species, which is the most stable tautomer in solution. The question of whether or not the ESI-mediated transfer from solution to gas phase is accompanied by isomerization of the species to the new ground structure has been the subject of much debate. Infrared action spectroscopy of the ions in the mass spectrometer has in recent years served as a primary tool to resolve gas-phase protonation sites [38,40-42,44,45] and other structural issues, among others in drug molecules, see e.g. Refs. [44,46-48,48-52] and in sulfur containing compounds, see e.g. Refs. [53-59].

Regarding the sulfa drug molecules studied here, the protonation site in the gas phase was not a primary focus of any previous study and no IR spectra of the protonated species were previously reported, which allow unequivocal determination of the protonation site. Therefore, this contribution addresses the preferred gas-phase protonation sites of seven sulfa drugs, sulfanilamide (SA), sulfamethoxazole (SMX), sulfisoxazole (SIX), sulfamethizole (SMZ), sulfathiazole (STZ), sulfapyridine (SP), and sulfaguanidine (SG) (Fig. 1). We employed infrared multiple-photon dissociation (IRMPD) spectroscopy to record the IR spectra of the protonated sulfa drugs produced by ESI from a methanol solution. Density functional theory (DFT) calculations were used to derive the protonation site from the experimental IR spectra. 


\section{Methods}

\subsection{Experimental}

All sulfa drugs (Fig. 1) were purchased from SigmaAldrich and used without further purification. The samples were dissolved in methanol and a few drops $(\sim$ $0.7 \mathrm{vol} \%$ ) of formic acid were added to enhance protonation. Sample concentrations of $2-3 \mathrm{mM}$ were used. The IR spectroscopic experiments were conducted at the Free Electron Laser for Infrared eXperiments (FELIX [60]) facility in Nijmegen (NL). Infrared multiphoton dissociation (IRMPD) spectra of the gaseous protonated compounds were recorded in a Fourier-Transform Ion Cyclotron Resonance (FT-ICR) mass spectrometer that has previously been described [61]. Briefly, gaseous protonated sulfa drugs were generated in a Micromass Z-spray ESI source. The desolvated ions were trapped and accumulated in a hexapole ion trap before being guided towards a quadrupole bender and an octopole ion guide into the ICR cell. The kinetic energy of the ions is reduced just prior to capture in the ICR cell by switching the DC-bias voltage on the octopole rf guide [62]. This avoids the use of a gas pulse to stop the ions and hence any collisional heating; since, in addition, the residence time of the ions in the ICR cell amounts to several seconds, we estimate the ions to be approximately at room temperature.

After trapping in the ICR cell, the ions were massisolated and irradiated with multiple IR pulses from a pulsed OPO/OPA $(10 \mathrm{~Hz}, 12-15 \mathrm{~mJ}$ per pulse, 3100 $3700 \mathrm{~cm}^{-1}$, LaserVision) or a FEL $(10 \mathrm{~Hz}, 20-75 \mathrm{~mJ}$ per pulse, $520-1750 \mathrm{~cm}^{-1}$, FELIX). After irradiation in the FT-ICR $\left(10^{-8}\right.$ mbar) a mass spectrum is recorded and the intensity of the IR-induced fragments as well as the remaining precursor ion is recorded. Irradiation times were chosen between 3 and $13 \mathrm{~s}$ based on the susceptibility of the compounds to fragmentation. Shorter irradiation times $(3-4 \mathrm{~s})$ were chosen for the spectra recorded with FELIX. To enhance the on-resonance dissociation yield for the OPO measurements, the ions are irradiated for $4-13 \mathrm{~ms}$ with the output of a $30 \mathrm{~W} \mathrm{cw} \mathrm{CO}_{2}$ laser directly after each OPO pulse [42]. The IR source was scanned through the region of interest in $5 \mathrm{~cm}^{-1}$ steps. The frequency was determined with a wavemeter for the OPO/OPA and a grating spectrometer for FELIX. The parent and fragment ion peaks were integrated and the fragmentation yield was calculated to reconstruct the IR spectra. All spectra are plotted as natural logarithm of the fragmentation yield assuming pseudo first order kinetics for the photofragmentation: $S=-\ln \left(1-\left[\sum I_{\text {fragments }} /\left(\sum I_{\text {fragments }}+\sum I_{\text {parent }}\right)\right]\right)$ [63]. The yield was linearly corrected for frequencydependent variations in the laser pulse energy $[47,64]$.

\subsection{Computational}

The Gaussian suite of programs (Gaussian 09, Rev. D.01) [65] was used to carry out all DFT calculations. The M06-2X functional [66] in conjunction with the $6-311++\mathrm{G}(3 \mathrm{df}, 3 \mathrm{pd})$ basis set $[67-70]$ was used. Tight convergence criteria were used for the geometry optimizations. Subsequently, harmonic IR spectra were calculated, frequencies were scaled, and stick spectra were convoluted with a Gaussian lineshape function $\left(\mathrm{FWHM}=20 \mathrm{~cm}^{-1}\right)$. For spectra in the fingerprint range a scale factor of 0.980 was adopted. Scaling factors for $\mathrm{N}-\mathrm{H}$ stretches may depend strongly on the type of $\mathrm{NH}$ moiety and the degree of H-bonding [71] and the use of a uniform scaling factor in this frequency range often gives disappointing results. Moreover, for the charged (protonated) systems studied here, deviations likely become worse [72], because intramolecular interactions are stronger and the degree of proton sharing between two Lewis basic sites increases [73,74]. Furthermore, note that scaling factors reported in the literature have almost exclusively been derived for test sets of neutral molecules. We have therefore employed ad hoc scaling factors for the spectra in the 3 micron range, which are chosen such that visually the best match is obtained; these scaling factors are given in the caption of each figure.

Geometries were also optimized in the presence of methanol as solvent to evaluate the influence of the solvent on the relative stability of different protonation sites. To mimic bulk solvation the integral equation formalism variant polarizable continuum model (IEFPCM) method [75] was used.

\section{Results and discussion}

The goal of the present study was to determine the protonation site of seven sulfa drugs (Fig. 1) in the gas phase. IRMPD spectra were recorded for all compounds in the NH stretch region. IRMPD spectra are usually close to linear absorption spectra, thus allowing for a direct comparison of calculated and experimental spectra to determine the protonation site. For three of the systems (SMZ, SMX, and SP), IRMPD spectra were also recorded in the fingerprint region to confirm the assignment based on the NH stretch vibrations. Other authors have employed the strong vibrational transitions associated with the $\mathrm{SO}_{2}$ group in this range for structural elucidation of sulfones [76,77], although we do not focus on these bands in this work.

Before discussing the IRMPD spectra, we briefly report the observed IR-induced dissociation of the sulfa drugs. A characteristic fragment ion signal at m/z 156 was detected for all sulfa drugs. This ion has previously been observed and identified as the sulfanilyl fragment, $\mathrm{H}_{2} \mathrm{~N}-\mathrm{C}_{6} \mathrm{H}_{4}-\mathrm{SO}_{2}^{+}[15,18,19]$. Its high abundance is attributed to the high stability of the sulfanilyl cation, which derives from efficient charge delocalization as suggested by the mesomeric structures shown in Fig. 2a. For all molecules except SA, a fragment at $\mathrm{m} / \mathrm{z} 108$ was also observed, due to SO loss from the sulfanilyl fragment ion $[15,16,18]$. For SMZ, SIX, $\mathrm{SP}$ and SG we further detected a fragment at $\mathrm{m} / \mathrm{z}$ 92, which can be attributed to formation of an anilinium 
a

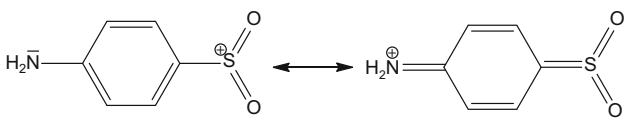

b
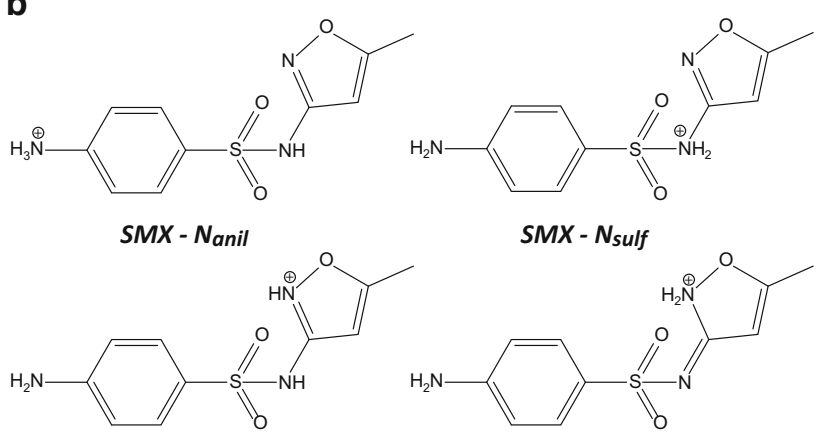

SMX $-N_{\text {htc }}$

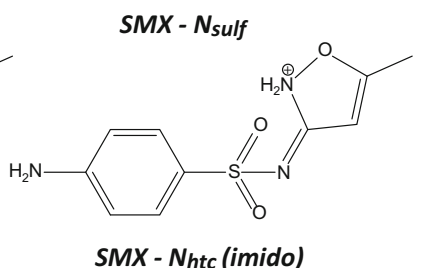

Fig. 2 a Resonance structures for the sulfanilyl cation. b Protonation isomers for SMX: anilinic N (top left, shown for amido tautomer), sulfanamide nitrogen (top right), heterocyclic nitrogen (bottom left) and heterocylic nitrogen of the imido tautomer (bottom right). Note that the chosen nomenclature refers to amido tautomers by default

carbocation [15] or a ring-expanded azatropylium ion [18]. For SMX, SIX and SG, we also observed additional fragments when irradiating with frequencies in the NH stretch region. SG also produced a fragment ion at $\mathrm{m} / \mathrm{z}$ 60. For SMX, we observed seven additional fragment masses in agreement with the results presented in Ref. [78]. SMX was the only molecule studied for which the $\mathrm{m} / \mathrm{z} 156$ fragment was not the dominant fragment. The main photofragment was observed at $\mathrm{m} / \mathrm{z} 188$, followed in intensity by a photofragment at $\mathrm{m} / \mathrm{z} 147$. This suggests that the main photodissociation pathway for SMX is different from that of the other sulfa drugs. The photofragment at $\mathrm{m} / \mathrm{z} 188$ is probably due to loss of $\mathrm{H}_{2} \mathrm{SO}_{2}$ similar to what was reported for CID of SP [17] and the loss of 66 Da observed for some sulfa drugs [15]. For SP, loss of 66 Da was also observed, but it was not the dominant photofragment. This dissociation/rearrangement pathway is possible for all sulfa drugs except SA, but was only observed for SMX and SP under our experimental conditions. Irradiation with FELIX generally led to the observation of more fragments likely due to sequential photofragmentation.

The most probable protonation sites of $\mathrm{SA}$ are the anilinic and sulfonamide $\mathrm{NH}_{2}$ groups and the $\mathrm{SO}_{2}$ group. For the derivatives of sulfanilamide, additional protonation sites are available, and especially the hetero-atoms in the heterocycle form reasonable alternatives (see Fig. 2). These likely candidates were computationally investigated by optimizing their structures also taking into consideration that different conformers might exist for a given protonation isomer. Table 1 lists the relative Gibbs free energies for a selection of protonated structures. Harmonic IR spectra were calculated for all structures and compared with the experimental
Table 1 Relative Gibbs free energies $(\mathrm{kcal} / \mathrm{mol})$ at $298.15 \mathrm{~K}$ of the protonated sulfa drugs in the gas phase and in methanol

\begin{tabular}{|c|c|c|}
\hline & $\Delta G$ & $\Delta G$ in $\mathrm{MeOH}$ \\
\hline \multicolumn{3}{|l|}{$S A$} \\
\hline sulf $\mathrm{NH}_{2}$ & 0.0 & 5.6 \\
\hline $\mathrm{SO}_{2}$ & 4.0 & 13.9 \\
\hline anilinic $\mathrm{NH}_{2}$ & 6.3 & 0.0 \\
\hline \multicolumn{3}{|l|}{$S M X$} \\
\hline $\mathrm{N}_{\mathrm{htc}} \operatorname{conf} \mathrm{A}^{\mathrm{a}}$ & 0.0 & 0.0 \\
\hline $\mathrm{N}_{\mathrm{htc}} \operatorname{conf} \mathrm{B}$ & 6.2 & 1.5 \\
\hline anilinic $\mathrm{NH}_{2}$ & 24.3 & 2.6 \\
\hline \multicolumn{3}{|l|}{$S I X$} \\
\hline $\mathrm{N}_{\mathrm{htc}}$ & 0.0 & 0.0 \\
\hline anilinic $\mathrm{NH}_{2}$ & 19.9 & 2.5 \\
\hline \multicolumn{3}{|l|}{$S M Z$} \\
\hline $\mathrm{N}_{\mathrm{htc}} \operatorname{conf} \mathrm{A}^{\mathrm{a}}$ & 0.0 & 0.0 \\
\hline $\mathrm{N}_{\mathrm{htc}} \operatorname{conf} \mathrm{B}^{\mathrm{b}}$ & 1.4 & 0.6 \\
\hline $\mathrm{N}_{\mathrm{htc}} 2 \operatorname{conf} \mathrm{A}^{\mathrm{b}}$ & 2.2 & 0.1 \\
\hline $\mathrm{N}_{\mathrm{htc}} 2$ conf B & 8.5 & 1.2 \\
\hline anilinic $\mathrm{NH}_{2}^{\mathrm{c}}$ & 20.7 & 3.3 \\
\hline \multicolumn{3}{|l|}{ STZ } \\
\hline $\mathrm{N}_{\mathrm{htc}} \operatorname{conf} \mathrm{A}^{\mathrm{a}}$ & 0.0 & 0.0 \\
\hline $\mathrm{N}_{\mathrm{htc}} \operatorname{conf} \mathrm{B}^{\mathrm{b}}$ & 3.7 & 0.8 \\
\hline anilinic $\mathrm{NH}_{2}^{\mathrm{c}}$ & 22.8 & 6.7 \\
\hline \multicolumn{3}{|l|}{$S P$} \\
\hline $\mathrm{N}_{\mathrm{htc}} \operatorname{conf} \mathrm{A}^{\mathrm{a}}$ & 0.0 & 0.0 \\
\hline $\mathrm{N}_{\text {htc }} \operatorname{conf} \mathrm{B}$ & 6.3 & 2.3 \\
\hline anilinic $\mathrm{NH}_{2}^{\mathrm{c}}$ & 27.9 & 11.6 \\
\hline \multicolumn{3}{|l|}{$S G$} \\
\hline sulf $\mathrm{N}$ & 0.0 & 0.0 \\
\hline anilinic $\mathrm{NH}_{2}{ }^{\mathrm{c}}$ & 21.5 & 7.8 \\
\hline
\end{tabular}

Not all possible protonation sites are listed, but only the lowest-energy structures and for comparison protonation at the anilinic $\mathrm{NH}_{2}$ group. All calculations were carried out at the M06-2X/6-311++G(3df,3pd) level of theory. Given is in each case the name of the group protonated. "htc" denotes the different heterocycles

${ }^{\text {a }} \mathrm{NH}_{\text {htc }} \cdots$ O hydrogen bond

${ }^{\mathrm{b}} \mathrm{S}_{\mathrm{htc}} \cdots \mathrm{O}$ interaction

${ }^{\mathrm{c}}$ Other proton in imido position

IRMPD spectra to determine the actual isomer present in the ion population.

Sulfanilamide (SA) For SA in aqueous solution, the anilinic amine moiety has been identified as the protonation site [20]. Calculations employing the polarizable continuum model (PCM) show that this is indeed the most stable protonated species in solution (Table 1). In contrast, in the gas phase, protonation at the sulfonamide $\mathrm{NH}_{2}$ group is computed to yield the lowestenergy species, with protonation at the anilinic amine being higher in energy by a significant margin of $6.3 \mathrm{kcal} / \mathrm{mol}$. Interestingly, the DFT calculations also show that protonation at one of the oxygen atoms is preferred over protonation at the anilinic $\mathrm{NH}_{2}$, lying only $4.0 \mathrm{kcal} / \mathrm{mol}$ higher than protonation at the sulfonamide $\mathrm{NH}_{2}$. Comparison of the calculated gas-phase IR spectra for the different protonation isomers of sulfanil- 

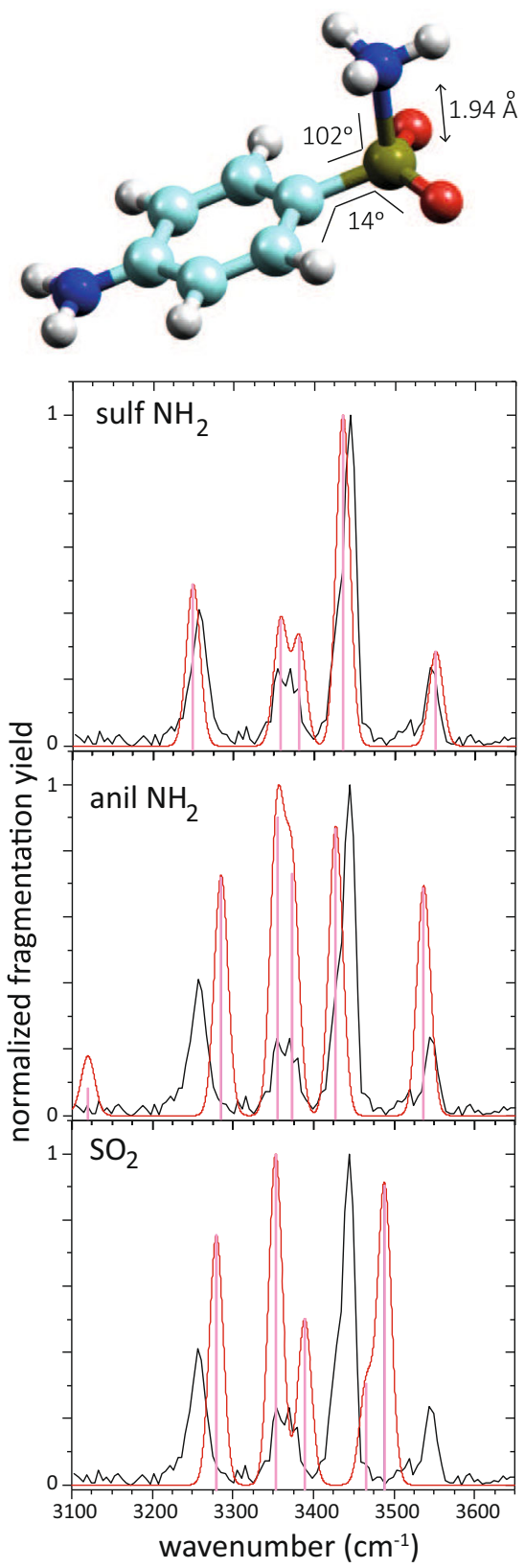

Fig. 3 Comparison of the experimental IRMPD spectrum (black) of protonated SA compared with computed IR spectra (red) for three protonation isomers. Frequency scaling factors are $\mathrm{SA}$ protonated at the sulfonamide $\mathrm{NH}_{2}(0.950)$, the anilinic $\mathrm{NH}_{2}(0.966)$, and the $\mathrm{SO}_{2}$ group (0.926). The computed 3D-structure with key structural parameters of the assigned sulfonamide protonated species is shown on top

amide (SA) with the experimental IRMPD spectrum in Fig. 3 enables us to unambiguously establish the gasphase protonation site as the sulfonamide $\mathrm{NH}_{2}$ group. Apparently, the system adopts its gas-phase structure upon transfer from solution to the gas phase in the ESI source.

The differences between gas-phase and solutionphase protonation sites can be rationalized in terms of charge localization. Protonation at the anilinic $\mathrm{NH}_{2}$ group leads to the positive charge being strongly localized on this nitrogen atom. Interaction with polar solvents disperses the charge in solution, but not in the gas phase, where such structures are relatively high in energy $[44,45]$. Placing the proton on the sulfonamide $\mathrm{NH}_{2}$-group generates a species that resembles a sulfanilyl cation and a neutral ammonia molecule, where the positive charge is efficiently delocalized in the sulfanilyl fragment (Fig. 2a). The computed structure of this protonation isomer is shown in the top panel of Fig. 3, with key structural parameters indicated. The nearly planar sulfanilyl fragment (CCSO dihedral angle is $14^{\circ}$ ) and nearly perpendicularly attached $\mathrm{NH}_{3}$ (CSN angle is $102^{\circ}$ ) testify of the suggested sulfanilyl ${ }^{+}-\mathrm{NH}_{3}$ structure. Other indications are the unusually long $\mathrm{S}-\mathrm{N}$ bond (1.94 $\AA$ versus $1.77 \AA$ typical [79]) and the Mulliken charge of only 0.38 on the $\mathrm{NH}_{3}$ group versus 0.62 on the sulfanilyl fragment. Hence, we conclude that SA is an example of a compound which relaxes to the most stable gas-phase structure during transfer from solution in the ESI source. The environment, i.e. solution versus gas phase, plays a crucial role in stabilization of the two protonation isomers of SA.

For derivatives of sulfanilamide studied here (see Fig. 1), protonation of the sulfonamide $\mathrm{N}$ in the gas phase was suggested in the literature based on MS/MS results [18]. However, although the observed fragments indeed excluded the possibility of protonation at the anilinic $\mathrm{NH}_{2}$ group, it did not exclude the possibility of protonation at the substituent $\mathrm{R}$ group, which could therefore be an alternative to protonation at the sulfonamide nitrogen. Here we investigate the protonation site of these systems spectroscopically. For the following discussion, we note that the distinction between the amido and imido tautomers [35] vanishes upon protonation at the sulfonamide nitrogen of the neutral imido tautomer or at the substituent group nitrogen of the neutral amido tautomer. Distinction of the two tautomers remains for protonation at the anilinic nitrogen and for protonation of the amido tautomer on the sulfonamide nitrogen and protonation at the R-group nitrogen of the imido tautomer, forming species with a quaternary nitrogen (see Fig. 2b).

Sulfamethoxazole (SMX) and sulfisoxazole (SIX) Despite their similar molecular structures, SMX and SIX have significantly different $3-\mu \mathrm{m}$ IR spectra, see Fig. 4 . Nevertheless, in both cases comparison of experimental and calculated spectra leads to the conclusion that the nitrogen atom in the heterocycle $\left(\mathrm{N}_{\mathrm{htc}}\right)$ is protonated, with the sulfonamide group in the amido tautomer, i.e. configuration SMX-N $\mathrm{N}_{\text {htc }}$ in Fig. 2b. The protonation isomers $\mathrm{SMX}-\mathrm{N}_{\text {sulf }}$ and $\mathrm{SMX}-\mathrm{N}_{\text {htc }}$-imido involving quaternary nitrogen atoms (Fig. 2b), which are not listed in Table 1, are 17 and $33 \mathrm{kcal} / \mathrm{mol}$ higher in energy, respectively. Moreover, their computed spectra match poorly (not shown).

Two conformers exist for $\mathrm{N}_{\text {htc }}$ protonated SMX, differing in the orientation of the oxazole substituent, see bottom left panel of Fig. 4. Conformer A allows for a 

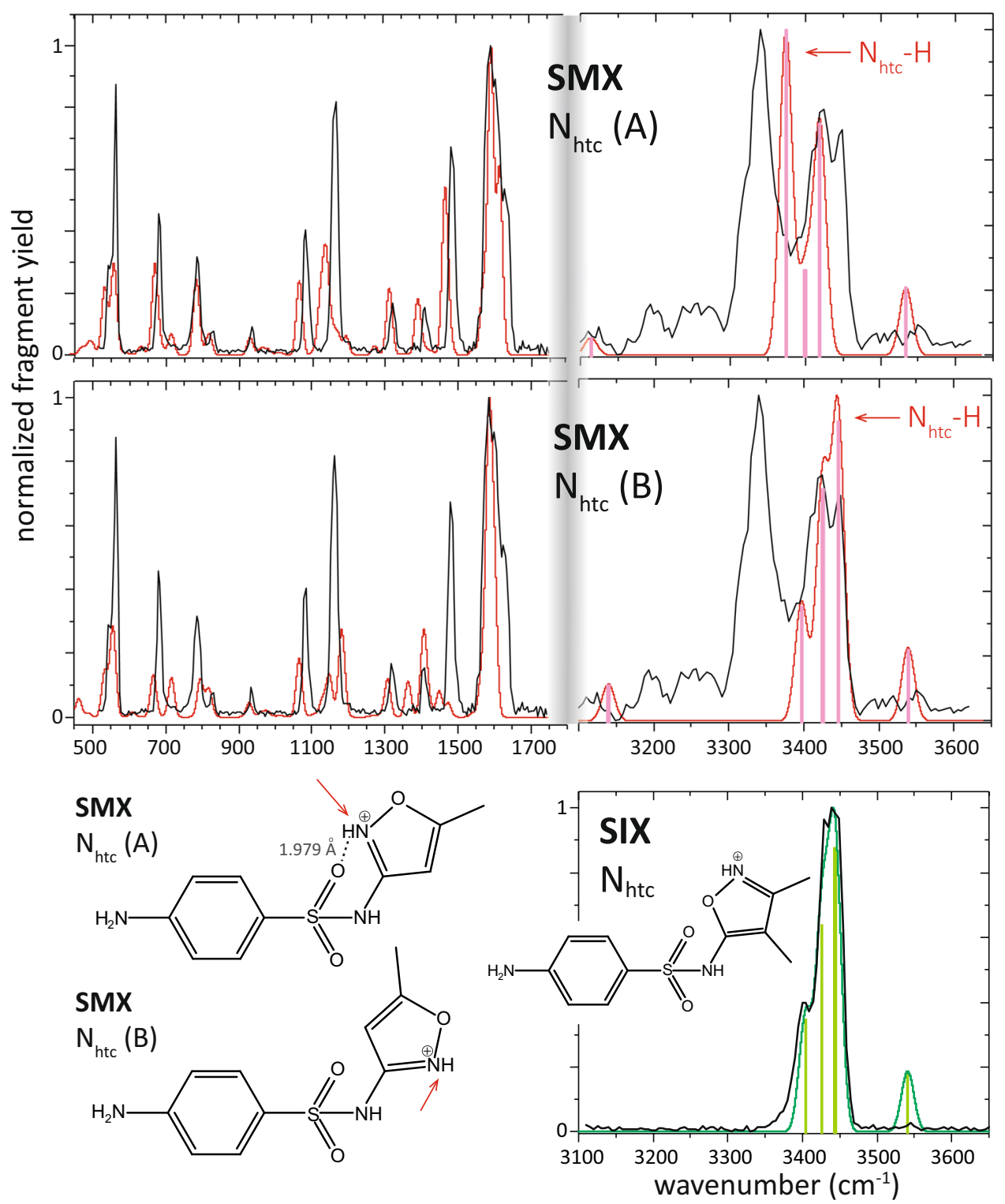

Fig. 4 Comparison of the experimental IRMPD spectrum (black) of SMX (amido tautomer) protonated at the heterocycle $\mathrm{N}$ atom for conformers $\mathrm{A}$ and $\mathrm{B}$. The most notable difference between the two conformers is the ability of $\mathrm{A}$ to form an $\mathrm{N}_{h t c} \mathrm{H} . \mathrm{O}=\mathrm{S}$ hydrogen bond, which causes a significant redshift of the $\mathrm{N}_{h t c}-\mathrm{H}$ stretch mode, as indicated by the red arrows. Scaling factor is 0.980 in the fingerprint range and 0.942 (conformer A) and 0.944 (conformer B) in the NH stretch range. The bottom panel shows a comparison of the experimental IRMPD spectrum of protonated SIX (black) and its computed IR spectrum, where protonation is on the $\mathrm{N}_{\mathrm{htc}}$ atom (green, 0.944); hydrogen bonding of this proton with the sulfonamide oxygens is not possible for SIX

hydrogen bond (1.98 $\AA$ ) between the heterocycle protonation site and one of the sulfonamide oxygen atoms. In conformer B, this hydrogen bond cannot form, which comes at an energetic penalty of about $6 \mathrm{kcal} / \mathrm{mol}$. The spectral comparisons in the top two panels indicate that the lower-energy conformer $\mathrm{A}$ is the one formed in the mass spectrometer. In the $\mathrm{NH}$ stretching range of the spectrum, the $\mathrm{N}_{\mathrm{htc}}-\mathrm{H}$ stretching mode shows a clear redshift in conformer A, induced by the hydrogen bonding, as compared to conformer B. Clearly, the experimentally observed redshift is substantially larger than what is predicted by the harmonic frequency cal- culation, showing that the use of a single scaling factor has its limitations in the analysis of NH-stretch modes [71]. In order to validate our assignment, the IR spectrum was also recorded in the $520-1750 \mathrm{~cm}^{-1}$ region. Indeed, the agreement between experimental and theoretical spectra is clearly better for conformer A than for conformer B.

The different spectral signatures of SMX and SIX can now be understood in terms of this intramolecular hydrogen bond between the $\mathrm{N}_{\mathrm{htc}}$ proton and the sulfonamide oxygen. In SIX, this hydrogen bond cannot form irrespective of the orientation of the isoxazole 
substituent group (see bottom right panel of Fig. 4). The IR spectrum of protonated SIX matches well with the computed spectrum of the $\mathrm{N}_{\text {htc }}$ protonated species. Moreover, it is similar to the computed spectrum of conformer B of $\mathrm{N}_{\mathrm{htc}}$-protonated SMX. We conclude that gas-phase protonation of both SMX and SIX occurs at the $\mathrm{N}_{\mathrm{htc}}$ site of the amido tautomer.

Sulfamethizole (SMZ) and sulfathiazole (STZ) The experimental 3- $\mu \mathrm{m}$ IR spectra of SMZ and STZ shown in Fig. 5 resemble that of SMX. Compared to SMX the spectral features span a wider frequency range and features appear better separated. For SMZ and STZ three peaks are distinguishable in the range $3350-3500 \mathrm{~cm}^{-1}$. In addition, a weak transition at $3555 \mathrm{~cm}^{-1}$ is observed, which can be assigned to the asymmetric anilinic NH stretch vibration based on calculations and the IR spectrum of protonated SA. Furthermore, another relatively weak band is observed below $3200 \mathrm{~cm}^{-1}$. As predicted by the calculations, STZ displays symmetric and asymmetric $\mathrm{CH}$ stretch vibrations localized at the heterocycle around $3130 \mathrm{~cm}^{-1}$. Finally, an intense and broadened band is observed near $3300 \mathrm{~cm}^{-1}$ for SMZ and $3250 \mathrm{~cm}^{-1}$ for STZ, which in analogy with SMX is assigned as an $\mathrm{H}$-bonded $\mathrm{NH}$ stretch mode.

Comparison of calculated and experimental IR spectra suggests that the protonation site for these two molecules is the nitrogen atom of the heterocycle adjacent to the carbon atom connecting to the sulfonamide moiety $\left(\mathrm{N}_{\mathrm{htc}} 1\right)$, being in its amido tautomeric form. The assignment is corroborated by the fact that protonation at this site also corresponds to the energetically most favored structure (Table 1). The most stable conformer of this structure exhibits an $\mathrm{N}_{\mathrm{htc}} \mathrm{H} \cdots \mathrm{O}=\mathrm{S}$ hydrogen bond (conformer A), analogous to SMX, with computed H-bond lengths of $1.958 \AA$ for SMZ and $1.913 \AA$ for STZ. The redshifted NH stretch band near $3300 \mathrm{~cm}^{-1}$ in SMZ and $3250 \mathrm{~cm}^{-1}$ in STZ is again a sensitive diagnostic providing convincing evidence for this structure, even though quantitatively, the calculated IR spectra appear to underestimate the redshift. Conformer B has the heterocyclic substituent rotated by $180^{\circ}$ so that this hydrogen bond is absent; it corresponds to the second most stable structure for both SMZ and STZ. Compared to the global minimum, these structures have relative energies of $1.4 \mathrm{kcal} / \mathrm{mol}$ for SMZ and $3.7 \mathrm{kcal} / \mathrm{mol}$ for STZ. For SMZ, the next species in the energetic ordering is formed by protonation of the other nitrogen atom of the heterocycle substituent, $\mathrm{N}_{\text {htc }} 2$, which leads to a structure that is $2.2 \mathrm{kcal} / \mathrm{mol}$ higher in energy. For $\mathrm{STZ}$, the second most stable protonation site is the $\mathrm{SO}_{2}$ group $(\Delta \mathrm{G}=8.7 \mathrm{kcal} / \mathrm{mol})$.

Interestingly, for both SMZ and STZ, three distinguishable peaks are visible around $3400 \mathrm{~cm}^{-1}$, whereas two peaks are expected based on the computed spectrum for the lowest energy structure. Possibly, there is is a minor contribution from conformer B of the lowestenergy protomer. For SMZ, a contribution from a struc-

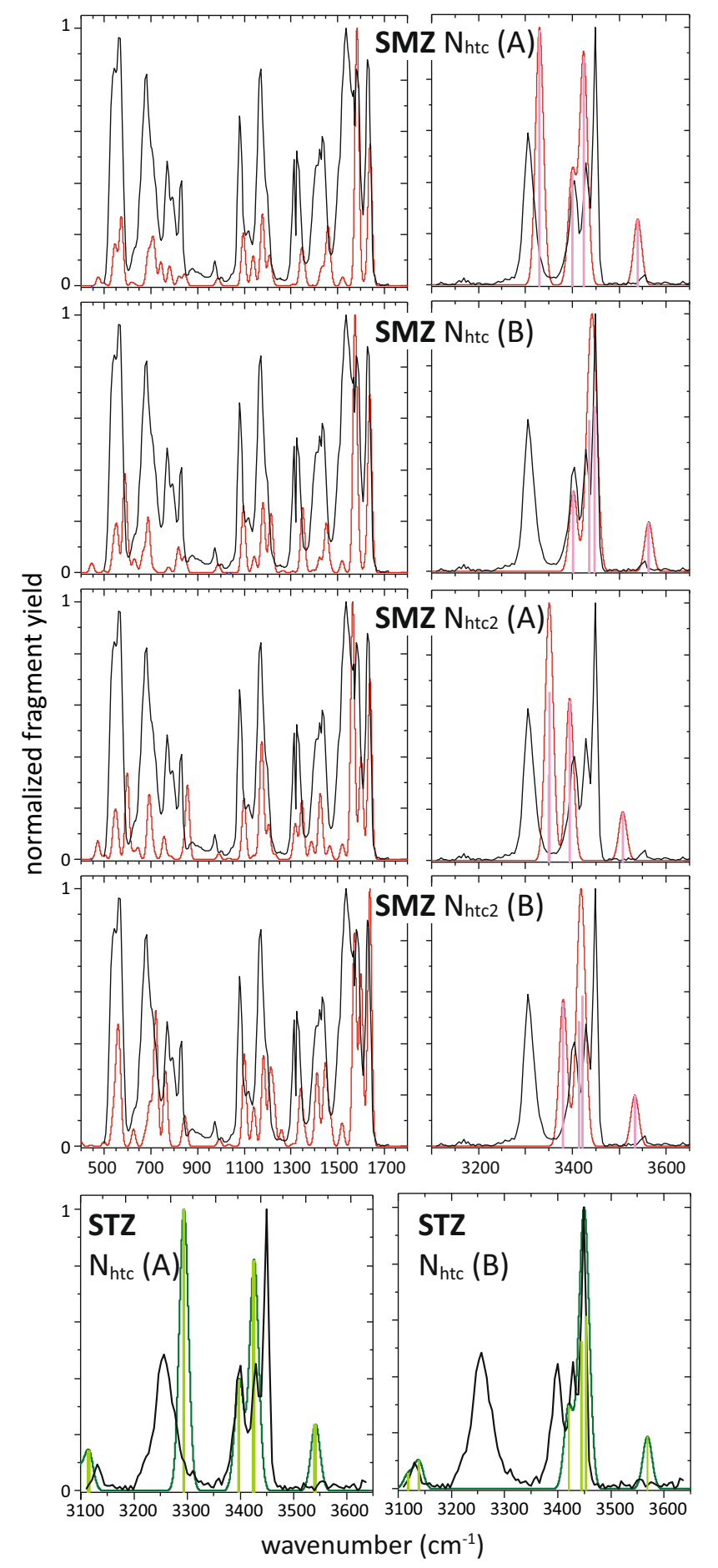

Fig. 5 Comparison of the experimental IRMPD spectrum (black) of protonated SMZ and computed spectra for protonation at the heterocycle $\mathrm{N}$ atom (Conf. A (0.944) and B $(0.950)$ ) and at the second $\mathrm{N}$ atom (conformer $\mathrm{A}(0.935)$ and B (0.944)). The bottom panels show the experimental spectrum of protonated STZ in the NH stretch range, compared with computed spectra for the $\mathrm{N}_{\text {htc }}$-protonated species in conformation A (0.944) and B (0.952) 
ture protonated at $\mathrm{N}_{\mathrm{htc} 2}$ could also explain the additional experimental band, but this is not possible for STZ. These structures are energetically disfavored, but calculated energy differences decrease substantially in solution (using the PCM method), even to less than $1 \mathrm{kcal} / \mathrm{mol}$ for some structures. Perhaps, the ion population does not reach the gas-phase thermal equilibrium upon desolvation in the ESI source, but remains partly reminiscent of the thermal equilibrium in solution. Another possibility is an accidental overtone or combination band which gains in intensity due to strong Fermi interaction with one of the NH-stretch fundamentals. Yet an alternative explanation is that the band is due to a combination band of the sulfonamide $\mathrm{NH}$ stretch and a low-energy torsional mode of about 25$30 \mathrm{~cm}^{-1}$; all sulfa drugs possess low-frequency torsions generally matching the observed frequency difference $[80,81]$.

For SMZ, an IRMPD spectrum was also recorded in the fingerprint region, as also shown in Fig. 5. The computed spectrum of the proposed structure, the amido tautomer protonated at the $\mathrm{N}_{\mathrm{htc}} 1$ nitrogen atom, matches the experimental IR spectrum in this frequency range very well if one considers the band frequencies; we suspect that the experimental intensity of the bands in the $1600 \mathrm{~cm}^{-1}$ range is underestimated due to some saturation on these strong bands. Close inspection of the match between experimental and computed IR spectra, especially in the $750-1050 \mathrm{~cm}^{-1}$ range, qualitatively reveals significant mismatches in band position for the species protonated at $\mathrm{N}_{\mathrm{htc}} 2$, indicating that its presence in the ion population is unlikely. However, a minor contribution from conformer $\mathrm{B}$ of the $\mathrm{N}_{\mathrm{htc}} 1$ protonated species cannot be excluded.

Evaluating the effect of solvation on the stability of the isomers of SMZ and STZ that are protonated at the anilinic $\mathrm{NH}_{2}$ group, shows in contrast to $\mathrm{SA}$, that protonation of the anilinic $\mathrm{NH}_{2}$ group is not favored in solution nor in the gas phase; protonation at the $\mathrm{N}$-atom in the heterocycle remains the most stable protonated species. Nevertheless, the energy difference between species protonated at the anilinic $\mathrm{NH}_{2}$ and at the heterocyclic $\mathrm{N}$ decreases substantially upon solvation: from 20.7 to $3.3 \mathrm{kcal} / \mathrm{mol}$ for SMZ and from 22.8 to $6.7 \mathrm{kcal} / \mathrm{mol}$ for STZ (see Table 1). On that note, it has previously been reported [32] that in oxalate, sulfate and selenate salts of SMZ, the anilinic $\mathrm{NH}_{2}$ group is protonated. Together with the present gas-phase results, this showcases again the large influence of the environment on the stabilization of the different cations of these sulfa drugs.

Sulfapyridine (SP) The IRMPD spectrum of protonated SP is shown in Fig. 6, compared with computed IR spectra for the two lowest-energy structures, conformers $\mathrm{A}$ and $\mathrm{B}$ of the pyridine nitrogen protonated amide tautomer. The computed fingerprint IR spectrum of conformer $\mathrm{A}$, featuring a hydrogen bond between the proton at the pyridine nitrogen and the sulfonamide oxygen, presents an excellent match with experiment. Hence, we assign this structure, being also

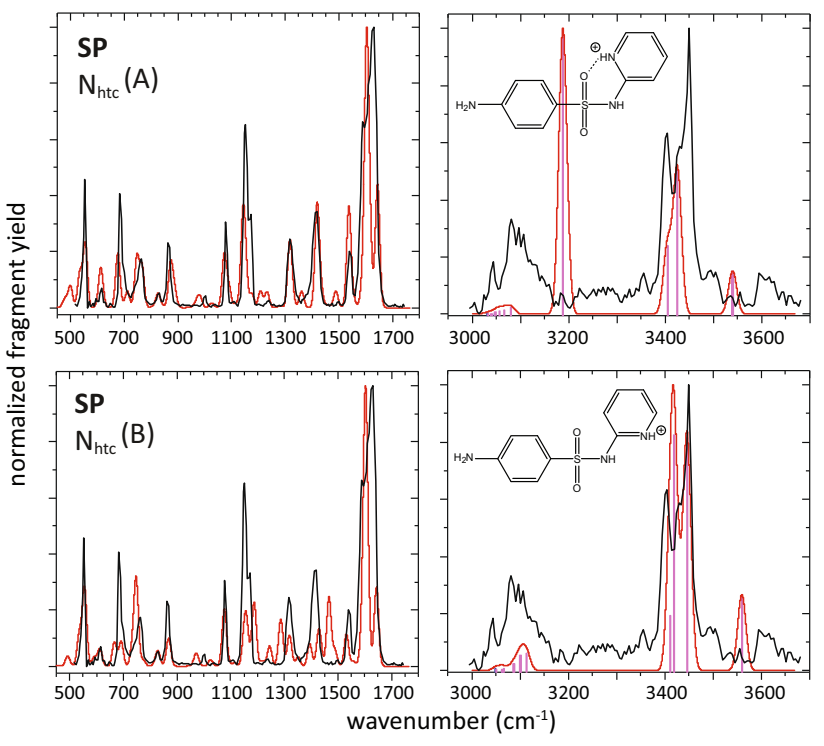

Fig. 6 Comparison of the experimental IRMPD spectrum (black) of protonated SP with computed spectra for conformer A and B of pyridine-protonated SP. Scale factor is is 0.980 in fingerprint region and 0.944 (a) and 0.950 (b) in the $\mathrm{NH}$ stretch range

the most stable structure, to the species present in the MS. In the hydrogen stretch range of the spectrum, the experiment reveals a strong but severely broadened band centered at $3100 \mathrm{~cm}^{-1}$, in the range of the aromatic $\mathrm{CH}$ stretches which are usually not that strong. We attribute this band to the $\mathrm{N}_{\mathrm{htc}} \mathrm{H}$ stretch vibration, which is strongly shifted and broadened due to the strong H-bond with the sulfonamide oxygen. Indeed, this $\mathrm{H}$-bond is stronger in protonated SP as compared with the other sulfa drugs studied here, because the 6 -membered pyridine ring positions the proton closer to the sulfonamide oxygen than in the systems with a 5 -membered heterocycle. The H-bond length for protonated SP is computed to be $1.81 \AA$ as compared to, for instance, $1.98 \AA$ for conformer A of protonated SMX. The $\mathrm{N}_{\text {htc }} \mathrm{H}$ stretch vibration for conformer $\mathrm{A}$ is calculated at $3190 \mathrm{~cm}^{-1}$; clearly, the scaled harmonic frequency calculations underestimate the $\mathrm{H}$-bond induced redshift for this vibration. In fact, protonated SP shows the largest redshift of this $\mathrm{NH}$ stretch vibration of all sulfa drugs presented here $(\mathrm{SMX}<\mathrm{SMZ}<\mathrm{STZ}<\mathrm{SP})$, which then agrees with this system having the strongest $\mathrm{H}$-bond and the largest broadening of this band. The redshift with respect to the harmonic frequency calculation is probably caused by the more anharmonic shape of the potential of this vibration due to hydrogen bonding, approaching the situation where the proton becomes shared between the two nucleophiles. Many examples are found in the literature for redshifts and broadening of transitions due to hydrogen bonding and proton sharing [82-86].

The only other species providing a reasonably matching IR spectrum is the pyridine $\mathrm{N}$ protonated system in conformation B. The lack of the strong $\mathrm{N}_{\mathrm{htc}} \mathrm{H} \cdots \mathrm{O}=\mathrm{S}$ 


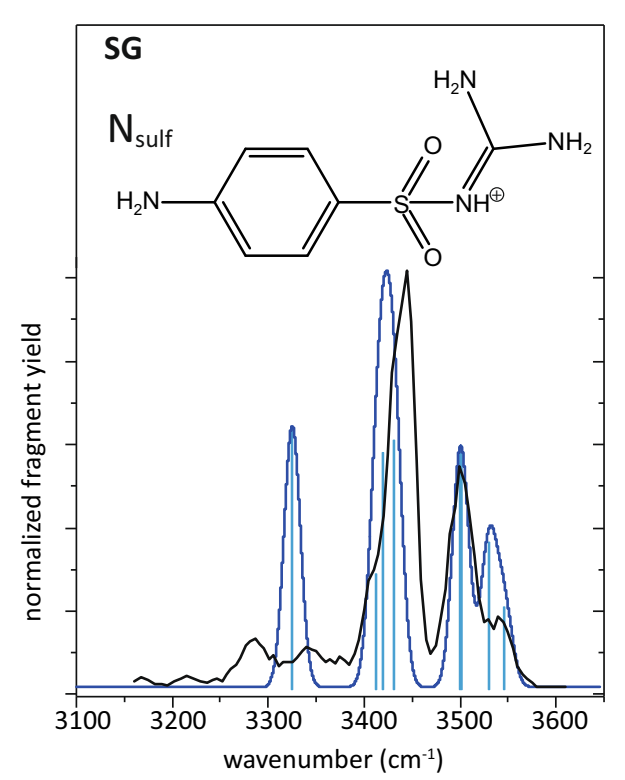

Fig. 7 IRMPD spectrum of protonated SG overlaid onto the computed spectrum of the structure shown. Neutral SG occurs in its imido tautomeric form and protonation is suggested to occur on the sulfonamide nitrogen. (Frequency scaling: 0.946)

hydrogen bond brings the $\mathrm{N}_{\mathrm{htc}} \mathrm{H}$ stretch mode back in the range of the other $\mathrm{NH}$ stretches between 3400 and $3500 \mathrm{~cm}^{-1}$. Although one could argue that the experimental band centered at $3100 \mathrm{~cm}^{-1}$ is due to the aromatic $\mathrm{CH}$ stretches, we believe that its intensity is too high for this assignment. Moreover, the spectrum in the fingerprint range does not match as closely as that computed for conformer A, which is also energetically more favorable.

Noteworthy, the IR spectrum of protonated SP also shows a shoulder at $3429 \mathrm{~cm}^{-1}$, in addition to the expected transitions for conformer A. This appears similar to the additional spectral feature observed for protonated SMZ and STZ. For SP, only one protonation isomer has a reasonably low relative energy and solvation effects do not suggest any other species or conformers having a low enough energy to contribute to the IR spectrum. This could indicate that the additional spectral feature is actually due to a (torsional) combination band.

Sulfaguanidine ( $S G$ ) Figure 7 shows the IRMPD spectrum recorded for protonated SG, the only compound in this study in which the $\mathrm{R}$ group is not an aromatic heterocycle. SG is also the only compound of the series of sulfa drugs presented here that is in its imido form as neutral molecule in the gas phase [87]. The only viable assignment based on the agreement between the calculated and experimental spectra is obtained for the structure protonated at the sulfonamide $\mathrm{N}$, shown in Fig. 7. This structure also corresponds to the global minimum in gas and solution phase according to the DFT calculations.
The agreement of calculated and experimental IR spectrum is generally convincing. The most prominent deviation is the intensity of the hydrogen-bonded $\mathrm{NH}$ stretch vibration computed near $3320 \mathrm{~cm}^{-1}$. The relative intensity of this transition is lower than calculated and it appears that there are actually two transitions in the experimental spectrum. In a previously recorded gas phase IR spectrum of neutral SG [87] it was shown that the experimentally observed relative intensity of the hydrogen bonded $\mathrm{NH}$ stretch vibration is markedly lower than calculated. Also in many IRMPD spectra, strongly hydrogen-bonded XH-stretches tend to broaden significantly and concomitantly show reduced peak intensity. The observation of an additional feature may again be due to an overtone or a combination band.

\section{Conclusion}

A set of seven gaseous protonated sulfa drugs was structurally characterized using IRMPD spectroscopy, particularly focusing on the site of gas-phase protonation. Even though the NH stretch region of the IR spectrum was usually diagnostic for the determination of the protonation site, the spectra in the fingerprint region for selected systems were useful for further confirmation, leading to reliable spectral assignments. SA and SG are protonated at the sulfonamide nitrogen atom. The preferred protonation site of the other sulfa drugs was found to be the nitrogen atom of the heterocyclic substituent group. With the exception of SA, the drug compounds show amido-imido tautomerism in their neutral form, with the amido tautomer being lowest in energy. Protonation then occurs at the position of the proton in the neutral imido tautomer (except for SG), i.e. in the protonated species the amido and imido positions are both protonated (see also Fig. 2). Note that this allows one to draw resonance structures with the formal charge on either the nitrogen atom of the heterocycle or of the sulfonamide moiety. Protonation at the heterocyclic nitrogen thus forms a resonance-stabilized cation.

For SA the preferred protonation site in the gas phase differs from the preferred protonation site in solution. Calculations employing the PCM method to account for solvent effects successfully predict this switch in protonation site. The most stable protonated species does not change for the other sulfa drugs, but the energetic ordering of the higher energy structures changes. Even in solution protonation of the anilinic $\mathrm{NH}_{2}$ group is not preferred in the sulfanilamide derivatives, nevertheless the difference in energy decreases dramatically going from gas phase to solution.

Acknowledgements An earlier version of this paper appeared as part of TU's Ph.D. Thesis, Ruhr Universität, Bochum, Germany. TU acknowledges support by the Cluster of Excellence RESOLV (EXC 1069) funded by the Deutsche Forschungsgemeinschaft. We gratefully acknowl- 
edge the Nederlandse Organisatie voor Wetenschappelijk Onderzoek (NWO) for the support of the FELIX Laboratory. Computational resources for this project were kindly supplied by the SurfSARA Supercomputer center in Amsterdam based on NWO Rekentijd grant 2019.062.

\section{Author contributions}

TU and JO conceived the study. TU and GB performed the experiments. Calculations were performed by TU. The manuscript was written by TU and JO, and revised by all authors.

Data Availibility Statement This manuscript has associated data in a data repository. [Authors' comment: Data associated with this paper is available upon request from the corresponding author.]

Open Access This article is licensed under a Creative Commons Attribution 4.0 International License, which permits use, sharing, adaptation, distribution and reproduction in any medium or format, as long as you give appropriate credit to the original author(s) and the source, provide a link to the Creative Commons licence, and indicate if changes were made. The images or other third party material in this article are included in the article's Creative Commons licence, unless indicated otherwise in a credit line to the material. If material is not included in the article's Creative Commons licence and your intended use is not permitted by statutory regulation or exceeds the permitted use, you will need to obtain permission directly from the copyright holder. To view a copy of this licence, visit http://creativecomm ons.org/licenses/by/4.0/.

\section{References}

1. G. Domagk, Ein Beitrag zur Chemotherapie der bakteriellen Infektionen Deut. Med. Wochenschr. 61, 250253 (1935)

2. J. Tréfouël, T. Tréfouël, F. Nitti, D. Bovet, Activité du p-aminophénylsulfamide sur l'infection streptococcique expérimentale de la souris et du lapin. C. R. Soc. Biol. Paris 120, 756-758 (1935)

3. N. Anand, Chapter 33: Sulfonamides and sulfons, in Burger's Medicinal Chemistry \& Drug Discovery, vol. 2, 5th edn., ed. by M.E. Wolff (Wiley-Interscience, New York, 1966)

4. G.M. Brown, The biosynthesis of folic acid: II. Inhibition by sulfonamides. J. Biol. Chem. 237, 536-540 (1962)

5. J.K. Seydel, Sulfonamides, structure-activity relationship, and mode of action. J. Pharm. Sci. 57, 1455-1478 (1968)

6. G.M. Brown, The biosynthesis of pteridines. Adv. Enzymol. Relat. Areas Mol. Biol. 35, 35-77 (1971)

7. A. Achari, D.O. Somers, J.N. Champness, P.K. Bryant, J. Rosemond, D.K. Stammers, Crystal structure of the anti-bacterial sulfonamide drug target dihydropteroate synthase. Nat. Struct. Biol. 4, 490-497 (1997)
8. M.-K. Yun, Y. Wu, Z. Li, Y. Zhao, M.B. Waddell, A.M. Ferreira, R.E. Lee, D. Bashford, S.W. White, Catalysis and sulfa drug resistance in dihydropteroate synthase. Science 335, 1110-1114 (2012)

9. P.H. Bell, R.O. Roblin Jr., Studies in chemotherapy. VII. A theory of the relation of structure to activity of sulfanilamide type compounds. J. Am. Chem. Soc. 64, 2905-2917 (1942)

10. W.D. Kumler, T.C. Daniels, The relation between chemical structure and bacteriostatic activity of sulfanilamide type compounds. J. Am. Chem. Soc. 65, 21902196 (1943)

11. R.S. Schnaare, A.N. Martin, Quantum chemistry in drug design. J. Pharm. Sci. 54, 1707-1713 (1965)

12. T. Fujita, C. Hansch, Analysis of the structure-activity relationship of the sulfonamide drugs using substituent constants. J. Med. Chem. 10, 991-1000 (1967)

13. J. Drews, Drug discovery: a historical perspective. Science 287, 1960-1964 (2000)

14. A.L. Boreen, W.A. Arnold, K. McNeill, Photochemical fate of sulfa drugs in the aquatic environment: sulfa drugs containing five-membered heterocyclic groups. Environ. Sci. Technol. 38, 3933-3940 (2004)

15. K. Kalgkou, F. Pullen, M. Harrison, A. Organ, A. Firth, G.J. Langley, Fragmentation pathways of sulphonamides under electrospray tandem mass spectrometric conditions. Rapid Commun. Mass Spectrom. 17, 2373-2379 (2003)

16. D. Song, H. Liu, A. Zhang, J. Qu, Fragmentation of typical sulfonamide drugs via heterolytic bond cleavage and stepwise rearrangement. RSC Adv. 4, 48426-48432 (2014)

17. Y. Liu, X. Zhang, Y. Ouyang, Z. Hu, L. Ma, J. Zhang, J. Lin, H. Chen, Trace detection of hormones and sulfonamides in viscous cosmetic products by neutral desorption extractive electrospray ionization tandem mass spectrometry. J. Mass Spectrom. 46, 794-803 (2011)

18. S. Pleasance, P. Blay, M.A. Quilliam, G. O'Hara, Determination of sulfonamides by liquid chromatography, ultraviolet diode array detection and ion-spray tandem mass spectrometry with application to cultured salmon flesh. J. Chromatogr. 558, 155-173 (1991)

19. M.E. Lindsey, M. Meyer, E.M. Thurman, Analysis of trace levels of sulfonamide and tetracycline antimicrobials in groundwater and surface water using solid-phase extraction and liquid chromatography/mass spectrometry. Anal. Chem. 73, 4640-4646 (2001)

20. W.D. Kumler, L.A. Strait, The ultraviolet absorption spectra and resonance in benzene derivativessulfanilamide, metanilamide, p-aminobenzoic acid, benzenesulfonamide, benzoic acid and aniline. J. Am. Chem. Soc. 65, 2349-2354 (1943)

21. S. Şanil, Y. Altun, N. Şanil, G. Alsancak, J.L. Beltran, Solvent effects on $\mathrm{p} K_{a}$ values of some substituted sulfonamides in acetonitrile-water binary mixtures by the UVspectroscopy method. J. Chem. Eng. Data 54, 30143021 (2009)

22. A. Borba, A. Gómez-Zavaglia, R. Fausto, Conformational landscape, photochemistry, and infrared spectra of sulfanilamide. J. Phys. Chem. A 117, 704-717 (2013)

23. J.L. Castro, M.R. Lopez-Ramirez, J.F. Arenas, J.C. Otero, Surface-enhanced Raman scattering of ben- 
zenesulfonamide and sulfanilamide adsorbed on silver nanoparticles. J. Raman Spectrosc. 43, 857-862 (2012)

24. A.C. Moffat, J.V. Jackson, M.S. Moss, B. Widdop, E.S. Greenfield (eds.), Clarke's Isolation and Identification of Drugs, 2nd edn. (The Pharmaceutical Press, London, 1986)

25. L. Geiser, Y. Henchoz, A. Galland, P.-A. Carrupt, J.L. Veuthey, Determination of $\mathrm{p} K_{a}$ values by capillary zone electrophoresis with a dynamic coating procedure. J. Sep. Sci. 28, 2374-2380 (2005)

26. D.D. Perrin, Dissociation Constants of Organic Bases in Aqueous Solution (Butterworths, London, 1965)

27. D.A. Williams, T.L. Lemke, (eds.), Foye's Principles of Medicinal Chemistry, 7th edn. (LWW, Philadelphia, 2002)

28. R.H. Manzo, M.M. de Bertorello, Isoxazoles I: protonation of isoxazole derivatives in aqueous sulfuric acid. J. Pharm. Sci. 62, 152-154 (1973)

29. A.A.M. Prabhu, G. Venkatesh, N. Rajendiran, Spectral characteristics of sulfa drugs: effect of solvents, $\mathrm{pH}$ and cyclodextrin. J. Solution Chem. 39, 1061-1086 (2010)

30. M. Swaminathan, S.K. Dogra, Solvent and pH dependence of absorption and fluoresence spectra of 5aminoindazole: biprotonic phototautomerism of singly protonated species. J. Am. Chem. Soc. 105, 6223-6228 (1983)

31. G. Smith, U.D. Wermuth, J.M. White, The 1:1 proton-transfer compound of sulfanilamide with 3,5dinitrosalicylic acid. Acta Crystallogr. E57, 1036-1038 (2001)

32. S.P. Thomas, S.P.K.P. Veccham, L.J. Farrugia, T.N. Guru Row, Conformational simulation of sulfamethizole by molecular complexation and insights from charge density analysis: role of intramolecular S. . O chalcogen bonding. Cryst. Growth Des. 15, 2110-2118 (2015)

33. J. Pratt, J. Hutchinson, C.L. Klein Stevens, Sulfapyridine(polymorph III), sulfapyridine dioxane solvate, sulfapyridine tetrahydrofuran solvate and sulfapyridine piperidine solvate, all at $173 \mathrm{~K}$. Acta Crystallogr. C67, 487-491 (2014)

34. T. Gelbrich, L. Threfall, A.L. Bingham, M.B. Hursthouse, Polymorph VI of sulfapyridine: interpenetrating two- and three-dimensional hydrogen-bonded nets formed from two tautomeric forms. Acta Crystallogr. C63, 323-326 (2007)

35. S.S. Chourasiya, D.R. Patel, C.M. Nagaraja, A.K. Chakraborti, P.V. Bharatam, Sulfonamide vs. sulfonimide: tautomerism and electronic structure analysis of N-heterocyclic arenesulfonamides. New J. Chem. 41, 8118-8129 (2017)

36. T.B. McMahon, P. Kebarle, Intrinsic acidities of substituted phenols and benzoic acids determined by gasphase proton-transfer equilibria. J. Am. Chem. Soc. 99, 2222-2230 (1977)

37. Z. Tian, X.-B. Wang, L.-S. Wang, S.R. Kass, Are carboxyl groups the most acidic sites in amino acids? Gasphase acidities, photoelectron spectra, and computations on tyrosine, p-hydroxybenzoic acid, and their conjugate bases. J. Am. Chem. Soc. 131, 1174-1181 (2009)

38. J.D. Steill, J. Oomens, Gas-phase deprotonation of phydroxybenzoic acid investigated by IR spectroscopy: solution-phase structure is retained upon ESI. J. Am. Chem. Soc. 131, 13570-13571 (2009)
39. Z. Tian, S.R. Kass, Gas-phase versus liquid-phase structures by electrospray ionization mass spectrometry. Angew. Chem. Int. Ed. 48, 1321-1323 (2009)

40. J. Schmidt, M.M. Meyer, I. Spector, S.R. Kass, Infrared multiphoton dissociation spectroscopy study of protonated p-aminobenzoic acid: does electrospray ionization afford the amino- or carboxy-protonated ion? J. Phys. Chem. A 115, 7625-7632 (2011)

41. T.M. Chang, J.S. Prell, E.R. Warrick, E.R. Williams, Where's the charge? Protonation sites in gaseous ions change with hydration. J. Am. Chem. Soc. 134, 1580515813 (2012)

42. M. Almasian, J. Grzetic, J. van Maurik, J.D. Steill, G. Berden, S. Ingemann, W.J. Buma, J. Oomens, Nonequilibrium isomer distribution of the gas-phase photoactive protein chromophore. J. Phys. Chem. Lett. 3, 2259-2263 (2012)

43. D. Schröder, M. Budesinsky, J. Roithová, Deprotonation of $p$-hydroxybenzoic acid: does electrospray ionization sample solution or gas-phase structures? J. Am. Chem. Soc. 134, 15897-15905 (2012)

44. S. Warnke, J. Seo, J. Boschmans, F. Sobott, J.H. Scrivens, C. Bleiholder, M.T. Bowers, S. Gewinner, W. Schöllkopf, K. Pagel, G. von Helden, Protomers of benzocaine: solvent and permittivity dependence. J. Am. Chem. Soc. 137, 4236-4242 (2015)

45. A.L. Patrick, A.P. Cismesia, L.F. Tesler, N.C. Polfer, Effects of ESI conditions on kinetic trapping of the solution-phase protonation isomer of $p$-aminobenzoic acid in the gas phase. Int. J. Mass Spectrom. 418, 148155 (2017)

46. M. Seydou, J.C. Gillet, X. Li, H. Wang, G.H. Posner, G. Grégoire, J.P. Schermann, K.H. Bowen, C. Desfrançois, Studies of protonated and anionic artemisinin in the gas-phase by infrared multi-photon dissociation and by negative ion photoelectron spectroscopies. Chem. Phys. Lett. 449, 286-290 (2007)

47. A. Lagutschenkov, J. Langer, G. Berden, J. Oomens, O. Dopfer, Infrared spectra of protonated neurotransmitters: dopamine. Phys. Chem. Chem. Phys. 13, 2815$2823(2011)$

48. C.C. He, B. Kimutai, X. Bao, L. Hamlow, Y. Zhu, S.F. Strobehn, J. Gao, G. Berden, J. Oomens, C.S. Chow, M.T. Rodgers, Evaluation of hybrid theoretical approaches for structural determination of a glycinelinked cisplatin derivative via infrared multiple photon dissociation (IRMPD) action spectroscopy. J. Phys. Chem. A 119, 10980-10987 (2015)

49. B. Chiavarino, M.E. Crestoni, S. Fornarini, D. Scuderi, J.-Y. Salpin, Interaction of cisplatin with adenine and guanine: a combined IRMPD, MS/MS, and theoretical study. J. Am. Chem. Soc. 135, 1445-1455 (2013)

50. J. Martens, V. Koppen, G. Berden, F. Cuyckens, J. Oomens, Combined liquid chromatography-infrared ion spectroscopy for identification of regioisomeric drug metabolites. Anal. Chem. 89, 4359-4362 (2017)

51. D. Corinti, M.E. Crestoni, B. Chiavarino, S. Fornarinim, D. Scuderi, J.-Y. Salpin, Insights into cisplatin binding to uracil and thiouracils from IRMPD spectroscopy and tandem mass spectrometry. J. Am. Soc. Mass Spectrom. 31, 946-960 (2020)

52. R.E. van Outersterp, J. Martens, G. Berden, V. Koppen, F. Cuyckens, J. Oomens, Mass spectrometry- 
based identification of ortho-, meta- and para-isomers using infrared ion spectroscopy. Analyst 145, 6162-6170 (2020)

53. J. Oomens, J.D. Steill, B. Redlich, Gas-phase IR spectroscopy of deprotonated amino acids. J. Am. Chem. Soc. 131, 4310-4319 (2009)

54. R.K. Sinha, B. Chiavarino, S. Fornarini, J. Lemaire, P. Maitre, M.E. Crestoni, Protonated sulfuric acid: vibrational signatures of the naked ion in the near- and midIR. J. Phys. Chem. Lett. 1, 1721-1724 (2010)

55. A.F. DeBlase, S.R. Kass, M.A. Johnson, On the character of the cyclic ionic H-bond in cryogenically cooled deprotonated cysteine. PCCP 16, 4569-4575 (2014)

56. R. Paciotti, C. Coletti, N. Re, D. Scuderi, B. Chiavarino, S. Fornarini, M.E. Crestoni, Serine O-sulfation probed by IRMPD spectroscopy. Phys. Chem. Chem. Phys. 17, 25891-25904 (2015)

57. R.K. Sinha, D. Scuderi, P. Maitre, B. Chiavarino, M.E. Crestoni, S. Fornarini, Elusive sulfurous acid: gas-phase basicity and IR signature of the protonated species. J. Phys. Chem. Lett. 6, 1605-1610 (2015)

58. A.L. Patrick, C.N. Stedwell, B. Schindler, I. Compagnon, G. Berden, J. Oomens, N.C. Polfer, Insights into the fragmentation pathways of gas-phase protonated sulfoserine. Int. J. Mass Spectrom. 379, 26-32 (2015)

59. B. Schindler, L. Barnes, C.J. Gray, S. Chambert, S.L. Flitsch, J. Oomens, R. Daniel, A.R. Allouche, I. Compagnon, IRMPD spectroscopy sheds new (infrared) light on the sulfate pattern of carbohydrates. J. Phys. Chem. A 121, 2114-2120 (2017)

60. D. Oepts, A.F.G. van der Meer, P.W. van Amersfoort, The free-electron-laser user facility FELIX. Infrared Phys. Technol. 36, 297-308 (1995)

61. J.J. Valle, J.R. Eyler, J. Oomens, D.T. Moore, A.F.G. van der Meer, G. von Helden, G. Meijer, C.L. Hendrickson, A.G. Marshall, G.T. Blakney, Free electron laserFourier transform ion cyclotron resonance mass spectrometry facility for obtaining infrared multiphoton dissociation spectra of gaseous ions. Rev. Sci. Instrum. 76, 023103-1-7 (2005)

62. N.C. Polfer, J. Oomens, D.T. Moore, G. von Helden, G. Meijer, R.C. Dunbar, Infrared spectroscopy of phenyl alanine $\mathrm{Ag}(\mathrm{I})$ and $\mathrm{Zn}(\mathrm{II})$ complexes in the gas phase. J. Am. Chem. Soc. 128, 517-525 (2006)

63. G. Berden, M. Derksen, K.J. Houthuijs, J. Martens, J. Oomens, An automatic variable laser attenuator for IRMPD spectroscopy and analysis of power-dependence in fragmentation spectra. Int. J. Mass Spectrom. 443, 1-8 (2019)

64. R.J. Nieckarz, J. Oomens, G. Berden, P. Sagulenko, R. Zenobi, Infrared multiple photon dissociation (IRMPD) spectroscopy of oxazine dyes. Phys. Chem. Chem. Phys. 15, 5049-5056 (2013)

65. M. J. Frisch, G. W. Trucks, H. B. Schlegel, G. E. Scuseria, M. A. Robb, J. R. Cheeseman, G. Scalmani, V. Barone, B. Mennucci, G. A. Petersson, H. Nakatsuji, M. Caricato, X. Li, H. P. Hratchian, A. F. Izmaylov, J. Bloino, G. Zheng, J. L. Sonnenberg, M. Hada, M. Ehara, K. Toyota, R. Fukuda, J. Hasegawa, M. Ishida, T. Nakajima, Y. Honda, O. Kitao, H. Nakai, T. Vreven, J. A. Montgomery, Jr., J. E. Peralta, F. Ogliaro, M. Bearpark, J. J. Heyd, E. Brothers, K. N. Kudin, V. N. Staroverov,
T. Keith, R. Kobayashi, J. Normand, K. Raghavachari, A. Rendell, J. C. Burant, S. S. Iyengar, J. Tomasi, M. Cossi, N. Rega, J. M. Millam, M. Klene, J. E. Knox, J. B. Cross, V. Bakken, C. Adamo, J. Jaramillo, R. Gomperts, R. E. Stratmann, O. Yazyev, A. J. Austin, R. Cammi, C. Pomelli, J. W. Ochterski, R. L. Martin, K. Morokuma, V. G. Zakrzewski, G. A. Voth, P. Salvador, J. J. Dannenberg, S. Dapprich, A. D. Daniels, Ö. Farkas, J. B. Foresman, J. V. Ortiz, J. Cioslowski, D. J. Fox, Gaussian, Inc., Gaussian 09, Revision D.01, Wallingford CT (2013)

66. Y. Zhao, D.G. Truhlar, The M06 suite of density functionals for main group thermochemistry, thermochemical kinetics, noncovalent interactions, excited states, and transition elements: two new functionals and systematic testing of four M06-class functionals and 12 other functionals. Theor. Chem. Acc. 120, 215-241 (2008). (M062X citation)

67. A.D. McLean, G.S. Chandler, Contracted Gaussianbasis sets for molecular calculations. I. 2nd row atoms row atoms, $z=11-18$. J. Chem. Phys. 72, 5639-5648 (1980)

68. K. Raghavachari, J.S. Binkley, R. Seeger, J.A. Pople, Self-consistent molecular orbital methods. XX. Basis set for correlated wave-functions. J. Chem. Phys. 72, 650654 (1980)

69. T. Clark, J. Chandrasekhar, G.W. Spitznagel, PvR Schleyer, Efficient diffuse function-augmented basis-sets for anion calculations. III. the $3-21+\mathrm{G}$ basis set for 1st-row elements, Li-F. J. Comput. Chem. 4, 294-301 (1983)

70. M.J. Frisch, J.A. Pople, J.S. Binkley, Self-consistent molecular orbital methods. 25. Supplementary functions for Gaussian basis sets. J. Chem. Phys. 80, 3265-3269 (1984)

71. M. Mons, E. Gloaguen, Isolated neutral peptides. Top. Curr. Chem. 364, 225-270 (2015)

72. P. Gilli, V. Bertolasi, V. Ferretti, G. Gilli, Covalent nature of the strong homonuclear hydrogen bond. study of the O-H...O system by crystal structure correlation methods. J. Am. Chem. Soc. 117, 909-915 (1994)

73. J. R. Roscioli, L. R. McCunn, M. A. Johnson, Quantum structure of the intermolecular proton bond. Science, 316, 249-254 (2007)

74. H.U. Ung, A.R. Moehlig, S. Khodagholian, G. Berden, J. Oomens, T.H. Morton, Proton-bridge motions in amine conjugate acid ions having intramolecular hydrogen bonds to hydroxyl and amine groups. J. Phys. Chem. A 117, 1360-1369 (2013)

75. J. Tomasi, B. Mennucci, R. Cammi, Quantum mechanical continuum solvation models. Chem. Rev. 105, 29993093 (2005)

76. D. Scuderi, E. Bodo, B. Chiavarino, S. Fornarini, M.E. Crestoni, Amino acid oxidation: a combined study of cysteine oxo forms by IRMPD spectroscopy and simulations. Chem. Eur. J. 22, 17239-17250 (2016)

77. P. Maitre, D. Scuderi, D. Corinti, B. Chiavarino, M.E. Crestoni, S. Fornarini, Applications of infrared multiple photon dissociation (IRMPD) to the detection of posttranslational modifications. Chem. Rev. 120, 3261-3295 (2020)

78. H.-Y. Wang, X. Zhang, Y.-L. Guo, X.-C. Dong, Q.H. Tang, L. Lu, Sulfonamide bond cleavage in ben- 
zenesulfonamides and rearrangement of the resulting $p$-aminophenylsulfonyl cations: application to a 2pyrimidinyloxybenzylaminobenzenesulfonamide herbicide. Rapid Commun. Mass Spectrom. 19, 1696-1702 (2005)

79. T. Chivers, R.S. Laitinen, Fundamental chemistry of binary S, N and ternary S, N, O anions: analogues of sulfur oxides and N, O anions. Chem. Soc. Rev. 46, 5182-5192 (2017)

80. T. Uhlemann, S. Seidel, C.W. Müller, Laser desorption single-conformation UV and IR spectroscopy of the sulfonamide drug sulfanilamide, the sulfanilamide.water complex, and the sulfanilamide dimer. Phys. Chem. Chem. Phys. 19, 14625-14640 (2017)

81. T. Uhlemann, S. Seidel, C.W. Müller, Site-specific binding of a water molecule to the sulfa drugs sulfamethoxazole and sulfisoxazole: a laser-desorption isomer-specific UV and IR study. Phys. Chem. Chem. Phys. 20, 68916904 (2018)

82. R.M. Badger, S.H. Bauer, Spectroscopic studies of the hydrogen bond. II. The shift of the $\mathrm{O}-\mathrm{H}$ vibrational frequency in the formation of the hydrogen bond. J. Chem. Phys. 5, 839-851 (1937)

83. C.M. Huggins, G.C. Pimentel, Systematics of the infrared spectral properties of hydrogen bonding systems: frequency shift, half width and intensity. J. Phys. Chem. 60, 1615-1619 (1956)
84. G.S. Denisov, J. Mavri, L. Sobczyk, Potential energy shape for the proton motion in hydrogen bonds reflected in infrared and NMR spectra. in Hydrogen BondingNew Insights, ed. by S.J. Grabowski (Springer, Dordrecht, 2006), pp. 377-416. https://doi.org/10.1007/ 978-1-4020-4853-1_10

85. Q. Gu, C. Trindle, J.L. Knee, Communication: Frequency shifts of an intramolecular hydrogen bond as a measure of the intermolecular hydrogen bond strength. J. Chem. Phys. 137, 091101-1-4 (2012)

86. J.M. Headrick, E.G. Diken, R.S. Walters, N.I. Hammer, R.A. Christie, J. Cui, E.M. Myshakin, M.A. Duncan, M.A. Johnson, K.D. Jordan, Spectral signatures of hydrated proton vibrations in water clusters. Science 308, 1765-1769 (2005)

87. S. Seidel, Einzelkonformationsspektroskopie von biologischen Bausteinen und ihren mikrosolvatisierten Clustern im Molekülstrahl [in German]. Ph.D. thesis, RuhrUniversität Bochum (2017) 